\title{
The Relationship between Admission Mean Platelet Vol.ume and Further Left Ventricular Function in Patients with STEMI Undergoing Primary PCI
}

\author{
A.Elbagoury, K.Elrabbat, R.Baioumy, A.Hegab and A.Elnajjarr \\ Cardiology Dept., Faculty of Medicine, Benha Univ., Benha,Egypt \\ E-mail: shaddow_hope@yahoo.com
}

\begin{abstract}
The aim of this study is to analyze the relationship between MPV on admission and left ventricular function in anterior STEMI patients undergoing primary PCI.

MPV is a parameter showing platelet activation and function. MPV is a strong, independent predictor for angiographic reperfusion and in-hospital mortality in patients underwent primary PTCA.

A total of 50 anterior STEMI patients who underwent successful primary PCI were included in this prospective cohort study conducted between January 2016 and December 2016. For all patients, admission MPV was recorded and transthoracic echocardiography was done before discharge. The patients were subdivided according to EF into 2 subgroups:

Group (I): 26 patients with $\mathrm{EF} \geq 50 \%$.

Group (II): 24 patients with $\mathrm{EF}<50 \%$.

There was a significant statistical difference between the two groups regarding the left ventricular function by Echo $(\mathrm{p}$ value $=0.002)$. There was no significant statistical difference between the two groups regarding major cardiac events during hospital stay $(\mathrm{P}$ value $=0.56)$. Regarding 6months follow up, there was no significant statistical difference between the two groups regarding CVS $(\mathrm{P}$ value $=0.17)$, but there was statistically significant difference regarding re-infarction, re-hospitalization and highly significant difference regarding HF (P:<0.001), in favor of group II characterized by high MPV.

In our study, we observed a negative relation between admission MPV and subsequent EF. For this reason, in acute anterior STEMI patients, a high MPV may play an alerting role for possible LV dysfunction.
\end{abstract}

Key words: Mean platelet vol.ume, ST elevation myocardial infarction.

\section{Introduction}

Primary percutaneous coronary intervention (PCI) is an extensively received treatment modality for patients with ST segment elevation myocardial infarction (STEMI). [1] ST segment elevation myocardial infarction (STEMI) is an important cause of morbidity and mortality in coronary artery disease. The management of patients with STEMI in the earliest times after symptom onset is considerably important in both the emergency service and in hospital period. [2]

Mean platelet vol.ume (MPV) is a machinecalculated measurement of the average size of platelets found in blood and is typically included in blood tests as part of the CBC. Mean platelet vol.ume (MPV) is an indicator of platelet activation and platelet functions. [3]

Platelet aggregation plays an important role in the pathogenesis of myocardial infarction. MPV, an indicator of platelet activation, is found to be higher in patients with coronary artery disease than in normal subjects. [4]

MPV is a parameter showing platelet activation and function [5]. Elevated mean platelet vol.ume in patients with MI is an important risk factor for recurrent infarction and death. MPV is a strong, independent predictor for angiographic reperfusion and six-month mortality in patients underwent primary PTCA [6].

According to previous studies, high MPV on admission have a negative effect on patency and TIMI frame count of the infarct related artery in MI patients treated with thrombolytic therapy [7]. In another study of patients with MI who underwent primary PTCA, the MPV was higher in patients with total occlusion of infarct related artery than in patients with partial occlusion. [8]

\subsection{Patients and methods}

A total of 50 patients who were admitted to National Heart Institute presenting with anterior STEMI and undergoing primary PCI with door to balloon time $<90$ minutes.

They were included in this prospective cohort study. Conducted between January 2016 and December 2016. The study population was divided into two groups according to LV systolic function after primary PCI; group I $n=26$ patients with $\mathrm{EF} \geq$ $50 \%$ and group II $\mathrm{n}=24$ patients with $\mathrm{EF}<50 \%$. Approval of ethical committee was obtained. Informed consent obtained from every patient.

\subsection{Inclusion criteria}

Patients with ST-segment elevation myocardial infarction anterior (STEMI) undergoing primary PCI 
with TIMI III flow result (door to balloon time $<90$ minutes).

\subsection{Statistical analysis}

Data were analyzed using Statistical Program for Social Science (SPSS) version 25.0 for windows (SPSS Inc., Chicago, IL, USA) and NCSS 12.0 for windows (NCSS LCC., Kaysville, UT, USA).

Quantitative data were expressed as mean \pm standard deviation (SD). Median and inter-quartile range (IQR) were also calculated for quantitative data. Qualitative data were expressed as frequency and percentage.

\section{Results and discussion}

A total of 50 patients were included in this prospective cohort study. Conducted between January 2016 and December 2016. The study population was divided into two groups according to $\mathrm{LV}$ systolic function after primary PCI; group I $n=26$ patients with $\mathrm{EF} \geq 50 \%$ and group II $\mathrm{n}=24$ patients with $\mathrm{EF}<50 \%$. Informed consent obtained from every patient.

\subsection{The study group demographic data and risk factors}

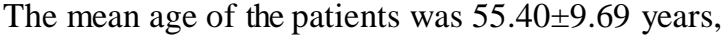
38 patients $(76 \%)$ were males and $12(24 \%)$ were females, 30 patients $(60 \%)$ were current smokers, 14 patients $(28 \%)$ were diabetic, 20 patients $(40 \%)$ were hypertensive, 4 patients $(8 \%)$ were dyslipidemic, 25 patients $(50 \%)$ with positive family history of CAD.

The patients were subdivided according to EF into 2 subgroups:

- Group (I): 26 patients with $\mathrm{EF} \geq 50 \%$.

- Group (II): 24 patients with $\mathrm{EF}<50 \%$.

\section{Demographic data, risk factors in each group}

- Group (I):

Composed of 26 patients with a mean age of the patients was $53.58 \pm 10.21$ years, 19 patients $(73.1 \%)$ were males, 16 patients $(61.5 \%)$ were current smokers, 6 patients $(23.1 \%)$ were diabetic, 11 patients $(42.3 \%)$ were hypertensive, 2 patients $(7.7 \%)$ were dyslipidemic, 13 patients $(50 \%)$ with positive family history of CAD.

- Group (II):

Composed of 24 patients with a mean age of the patients was $57.38 \pm 8.89$ years, 19 patients $(79.2 \%)$ were males, 14 patients $(58.3 \%)$ were current smokers, 8 patients $(33.3 \%)$ were diabetic, 9 patients $(37.5 \%)$ were hypertensive, 2 patients $(8.3 \%)$ were dyslipidemic, 12 patients $(50 \%)$ with positive family history of CAD.

There was no significant difference between the 2 groups regarding age, sex, smoking, diabetes mellitus, hypertension, dyslipidemia, and family history of CAD $(\mathrm{P}$ value $>0.05)$, Table $(1)$

Table (1) Demographic and clinical data in the study groups (I \& II)

\begin{tabular}{|c|c|c|c|c|c|c|}
\hline \multicolumn{7}{|l|}{ Groups } \\
\hline \multicolumn{2}{|c|}{$\begin{array}{l}\text { Variable } \\
\text { Demographic data }\end{array}$} & \multicolumn{2}{|c|}{$\begin{array}{l}\text { Group I }(n)=26 \\
X \pm S D\end{array}$} & \multicolumn{2}{|c|}{$\begin{array}{l}\text { Group II }(n)=\mathbf{2 4} \\
X \pm \text { SD }\end{array}$} & P-Value \\
\hline \multirow{2}{*}{\multicolumn{2}{|c|}{ Age }} & \multicolumn{2}{|c|}{$53.58 \pm 10.21$} & \multicolumn{2}{|c|}{$57.38 \pm 8.89$} & $0.144 \mathrm{NS}$ \\
\hline & & $\mathbf{N}$ & $(\%)$ & $\mathbf{N}$ & $\%$ & \\
\hline \multirow{2}{*}{ Gender } & Female & 7 & $(26.9 \%)$ & 5 & $(20.8 \%)$ & \multirow{2}{*}{$0.43 \mathrm{NS}$} \\
\hline & Male & 19 & $(73.1 \%)$ & 19 & $(79.2 \%)$ & \\
\hline HTN & & 11 & $(42.3 \%)$ & 9 & $(37.5 \%)$ & $0.47 \mathrm{NS}$ \\
\hline DM & & 6 & $(23.1 \%)$ & 8 & $(33.3 \%)$ & $0.31 \mathrm{NS}$ \\
\hline Smoking & & 16 & $(61.5 \%)$ & 14 & $(58.3 \%)$ & $0.52 \mathrm{NS}$ \\
\hline Dyslipid & & 2 & $(7.7 \%)$ & 2 & $(8.3 \%)$ & $0.66 \mathrm{NS}$ \\
\hline Family h & $y$ of CAD & 13 & $(50 \%)$ & 12 & $(50 \%)$ & $0.61 \mathrm{NS}$ \\
\hline Clinical & & & & & & \\
\hline Admissic & & & .75 & & & $0.275 \mathrm{NS}$ \\
\hline Admissi & & & & & & $0.541 \mathrm{NS}$ \\
\hline
\end{tabular}

- (N) Number, $\mathbf{X}=$ mean, $\mathbf{S D}=$ standard deviation, $\mathbf{N S}=$ non- significant, * significant, ** highly significant

3.2 MPV in both groups

Group (I): MPV mean value was $8.56 \pm 0.91 \mathrm{fL}$.

Group (II): MPV mean value was $9.48 \pm 0.97 \mathrm{fL}$.
There was a significant statistical difference between the two groups regarding the MPV (p value = 0.003). 


\subsection{CBC data in both groups:}

Group (I): Patients had mean hemoglobin value of $13.2 \pm 1.1 \mathrm{gm} / \mathrm{dL}$, mean WBCs count of $9.4 \pm 2.2$ (X1000/microlitre) and mean platelet count of $271.5 \pm 61.5$ (X1000/microlitre).

Group (II): Patients had mean hemoglobin value of $13.5 \pm 1.0 \mathrm{gm} / \mathrm{dL}$, mean WBCs count of $10.8 \pm 2.4$ (X1000/microlitre) and mean platelet count of $258.8 \pm 66.2$ (X1000/microlitre).

There was a significant statistical difference between the two groups regarding the WBCs count ( $\mathbf{p}$ value $=\mathbf{0 . 0 4 2})$ while there was no significant statistical difference between the two groups regarding hemoglobin value or platelets count $(\mathrm{P}$ value $=0.248$ and 0.473 respectively. Table (2).

\subsection{The major cardiovascular events during hospital stay}

Group (I): No patients had instent thrombosis,myocardial infarction or death.

Group (II): One patient $(4.1 \%)$ had instent thrombosis, while no patients had myocardial infarction or died.

There was no significant statistical difference between the two groups regarding major cardiac events during hospital stay. $(\mathrm{P}$ value $=0.56)$ Table (2).

Table (2) Comparison of in-hospital MACE between the study groups

\begin{tabular}{|c|c|c|c|}
\hline \multicolumn{4}{|c|}{ Groups } \\
\hline In-hospital MACE & $\begin{array}{l}\text { Group I } \\
\text { No }(\%)\end{array}$ & $\begin{array}{c}\text { Group II } \\
\text { No }(\%)\end{array}$ & P-value \\
\hline ISR & $\begin{array}{c}0 \\
(0.0 \%)\end{array}$ & $\begin{array}{c}1 \\
(4.1 \%)\end{array}$ & 0.56 \\
\hline MI & $\begin{array}{c}0 \\
(0.0 \%)\end{array}$ & $0(0.0 \%)$ & 0.56 \\
\hline Death & $\begin{array}{c}0 \\
(0.0 \%)\end{array}$ & $0(0.0 \%)$ & 0.56 \\
\hline
\end{tabular}

3.4 Six months major adverse cardiac events (6mo. MACE)

Group (I): One patient (3.8\%) had re-infarction, no patients had cerebro-vascular stroke, one patient (3.8\%) had heart failure, one patient $(3.8 \%)$ had rehospitalization and one patient (3.8\%) died.

Group (II): Three patients (12.5\%) had re-infarction, one patient $(4.1 \%)$ had cerebro-vascular stroke, five patients $(20.8 \%)$ had heart failure, four patients $(16.6 \%)$ had re-hospitalization and four patients $(16.6 \%)$ died.

There was no significant statistical difference between the two groups regarding CVS $(\mathrm{P}$ value $=$ 0.17 ), but there was statistically significant difference regarding re-infarction, re-hospitalization and mortality ( $\mathrm{P}=0.03,0.01$ and 0.01 respectively), highly significant difference regarding HF $(\mathrm{P}:<0.001)$.Table (3)

Table (3) Comparing the incidence of 6mo. MACE between the study groups.

\begin{tabular}{|c|c|c|c|}
\hline \multirow{2}{*}{ 6mo. MACE } & \multicolumn{2}{|c|}{ Groups } & \multirow{2}{*}{ P-value } \\
\cline { 2 - 4 } & $\begin{array}{c}\text { Group I } \\
\text { No (\%) }\end{array}$ & $\begin{array}{c}\text { Group II } \\
\text { No (\%) }\end{array}$ \\
\hline Re-infarction & 1 & 3 & $\mathbf{0 . 0 3}^{*}$ \\
\hline CVS & $(3.8 \%)$ & $(12.5 \%)$ & 0.17 \\
\hline HF & 0 & 1 & \multirow{2}{*}{$<\mathbf{0 . 0 0 1}^{* *}$} \\
& $(0.0 \%)$ & $5.1 \%)$ & $\mathbf{0 . 0 1}^{*}$ \\
\hline Re-hospitalization & 1 & $(20.8 \%)$ & $\mathbf{0 . 0 1}^{*}$ \\
\hline Mortality & $(3.8 \%)$ & 4 & $(16.6 \%)$ \\
\hline
\end{tabular}

Data are expressed as $\mathrm{n}(\%)$. Abbreviation: mo, months; MACE, major adverse cardiac events; CVS, cerebrovascular stroke; HF, heart failure. Categorical variables between two groups were compared Chi-square test. 


\subsection{Discussion}

Primary percutaneous coronary intervention (PCI) has been shown to be the most effective reperfusion strategy in the treatment of acute myocardial infarction (AMI). [9]

Mean platelet vol.ume (MPV) is an important indicator of platelet function. [10], larger platelets are more active and have higher thrombotic potential. Recent research indicates that high levels of MPV could be an independent predictor of ACS. This easily measurable parameter can not only be added to the already-known risk factors for acute myocardial infarction (AMI), but also may be used as a predictive tool and to determine patients' risk stratification. The results, however, from previous study samples examining the relationship between MPV and ACS are inconsistent due to variation in conditions.

Also, MPV as a marker of platelet reactivity has been shown to be predictive of unfavorable outcomes among survivors of ST elevation myocardial infarction (STEMI). We aimed to evaluate the value of admission of MPV, for the prediction of LV function, in patient with acute STEMI treated with primary PCI.

The present study was conducted on 50 patients (group I = 26 and group II = 24) admitted with acute anterior wall STEMI; all of them had undergone successful primary angioplasty. Careful history taking, clinical data on admission, full lab including CK, serum creatinine, ALT and AST, also left ventricular function by echo.

The present study showed statistically significant difference between the two groups as regard to relationship between admission MPV and LV systolic function after primary PCI $(\mathrm{P}$ value $=\mathbf{0 . 0 0 3})$

The present study also showed statistically significant difference between the two groups as regard to relationship between admission WBCs count and LV systolic function after primary PCI (P value $\mathbf{= 0 . 0 4 2}$ )

Upon six months follow up regarding MACE, there was statistically significant difference between the two groups as regard to re-infarction, rehospitalization and mortality ( $\mathrm{P}$ value was $\mathbf{0 . 0 3}, \mathbf{0 . 0 1}$ and 0.01 respectively) and highly significant difference regarding heart failure $(\mathrm{P}$ value $<0.001$ )

Regarding the same relationship previous study [6] concluded that, in anterior STEMI patients treated with percutaneous coronary intervention, increased MPV on admission is associated with impairment in left ventricular systolic function.

Moreover, their results indicate that preoperative MPV is an independent predictor of the MACE at 1year follow-up in the patients undergoing elective
PCI. Moreover, it may be useful for risk stratification in such cases.

In concordance with our results a previous study [12] who studied the associations of the mean platelet vol.ume (MPV) high-sensitivity cardiac troponin $\mathrm{T}$ (hs-cTnT) and N-terminal pro-B type natriuretic peptide (NT-proBNP) with the development of adverse outcomes after percutaneous coronary intervention (PCI), they concluded that MPV is a predictive marker for cardiac death after PCI; its predictive power for cardiac death is more useful in patients with myocardial injury or heart failure.

Our study agreed as well with previous study conducted a study on 310 patients with acute STEMI, in whom TIMI 3 flow was attained at the IRA after primary PCI. They used myocardial Blush Grade (MBG) to detect impaired coronary microvascular reperfusion. Their study results demonstrated that patients with higher MPV values on admission experienced poor myocardial blush grades, compared to those with lower MPV values $(10.5 \pm 1.3$ to $9.1 \pm 1$ fl, $\mathrm{P}<0.001$ ).

Our results were similar to with the study of previous study [15] which compared mean platelet vol.ume (MPV) and other indicators of 1524 patients with acute coronary syndrome (ACS). The level of MPV in ACS group was significantly higher than the control group $(9.5 \pm 1.34 \mathrm{fl}$ vs. $7.9 \pm 1.03 \mathrm{fl}, \mathrm{P}$ $<0.001)$. They found that MPV has been shown as an independent risk factor for early onset of AMI and can be applied to assist AMI diagnosis of ACS patients. Additionally, measuring MPV in conjunction with TnI levels can improve the diagnostic performance of TnI with higher sensitivity and specificity.

On the other Hand, our study disagreed with previous study [14] who studied the associations of the mean platelet vol.ume (MPV) with the development of adverse outcomes after percutaneous coronary intervention (PCI) and platelet reactivity. The results of this study show that MPV was a predictive marker for cardiac death after PCI; its predictive power for cardiac death was more useful in patients with ACS. In discordance with the previous studies, we did not identify any significant difference in in-hospital MACCEs of acute MI patients in low MPV vs. high MPV group. This difference can be due to limited number of patients in our study compared to the much bigger sample size they analyzed.

3. Conclusion

In our study, we observed a negative relation between admission MPV and subsequent EF. Compatible with previous studies, there was a 
significant relation between high white blood cells (WBC) count on admission and left ventricular EF.

Platelets play an important role in the pathogenesis of acute coronary syndrome. While platelets are spent during the MI, bone marrow produce and releases platelets to circulation. Mediators released from these rapidly produced immature platelets are more active. This has a negative effect on thrombotic process. (11)

High MPV is a biochemical indicator of platelet activation and negative impacts on thrombotic process.(12) Left ventricular systolic functions after MI is the most important factor in morbidity and mortality. There are several factors affecting left ventricular remodeling after MI, like irreversible microvascular injury triggered by ischemic reperfusion, full-thickness (transmural) necrosis, wide infarct area, re-obstruction or re-stenosis of the infarct related artery, left ventricular dys-synchrony, mitral regurgitation, inflammation and fibrosis, oxidative stress, neurohormonal activation (angiotensin II, aldosterone, BNP/ANP).

MPV is a parameter showing platelet activation and function1. Elevated mean platelet vol.ume in patients with MI is an important risk factor for recurrent infarction and death.(12) MPV is a strong, independent predictor for angiographic reperfusion, in-hospital and 6 months mortality in patients underwent primary PTCA.(13)

We found that patients with a LVEF $<50 \%$ had a higher admission MPV than other group. Therefore, we proposed that, the increase in MPV may have caused recurrent thrombosis and worsen microvascular perfusion, and thereby affected left ventricular functions.

In conclusion, these findings, although do not prove a direct relation, may suggest an indirect role of MPV in LV remodeling. For this reason, in acute anterior STEMI patients, a high MPV may play an alerting role for possible $\mathrm{LV}$ dysfunction.

Further studies are needed on this issue.

\section{Acknowledgement}

I would like to express my deepest gratitude and appreciation to all supervising team of professors and doctors for their valuable guidance and expert supervision, in addition to his great deal of support and encouragement. I really have the honor to complete this work under their supervision. God blesses them and keeps them a sun lightening the way for the scientific students.

Conflicts of Interest: no conflict of interest

\section{References}

[1] V Trkulja, S Car. On-admission serum uric acid predicts outcomes after acute myocardial infarction: systematic review and metaanalysis of prognostic studies. Croatian medical journal, vol. 53(2), pp. 162-172. 2012

[2] M Akpek, M Kaya, H Uyarel, M Yarlioglues, N Kalay, N., O Gunebakmaz, \& A Oguzhan, The association of serum uric acid levels on coronary flow in patients with STEMI undergoing primary PCI. Atherosclerosis, vol. 219(1), pp.334-341. 2011

[3] Y Yesil, M E Kuyumcu, M Cankurtaran, B Uz, A Kara, M K Kilic, \& S Ariogul, Increased mean platelet vol.ume (MPV) indicating the vascular risk in Alzheimer's disease (AD). Archives of gerontology and geriatrics, vol. 55(2), pp. 257260. 2012

[4] P M Bath, \& R J Butterworth,. Platelet size: measurement, physiology and vascular disease. Blood coagulation \& fibrinolysis: an international journal in haemostasis and thrombosis, vol. 7(2), pp. 157-161. 1996

[5] J F Martin, E A Trowbridge, G Salmon \& J Plumb,. The biological significance of platelet vol.ume: its relationship to bleeding time, platelet thromboxane B2 production and megakaryocyte nuclear DNA concentration. Thrombosis research, vol. 32(5), pp. 443-460. 1983

[6] Z Huczek, J Kochman, K J Filipiak, G J Horszczaruk, M Grabowski, R Piatkowski, \& G Opolski,. Mean platelet vol.ume on admission predicts impaired reperfusion and long-term mortality in acute myocardial infarction treated with primary percutaneous coronary intervention. Journal of the American College of Cardiology, vol. 46(2), pp. 284-290. 2005

[7] A Saatcı Yaşar,., E Bilen,., İ Yüksel,. U.Ö., Arslantaş, , F.Karakaş, , Ö.Kırbaş, , \& M Bilge,. Association between admission mean platelet vol.ume and coronary patency after thrombolytic therapy for acute myocardial infarction. Archives of the Turkish Society of Cardiology, vol. 38(2), pp. 85-89. 2010.

[8] O.Maden, , F.Kacmaz, , M. T Selcuk,.., , H Selcuk., F.Metin, , O Tufekcioglu,.., ... \& E.Ilkay, Relationship of admission haematological indices with infarct-related artery patency in patients with acute ST-segment elevation myocardial infarction treated with primary angioplasty. Coronary artery disease, vol. 18(8),pp. 639-644. 2007.

[9] H. V Barron,., L. J Bowlby,., T.Breen, , W. J Rogers,., J. G Canto,.., Y Zhang,., ... \& W. D WeaverUse of reperfusion therapy for acute 
myocardial infarction in the United States: data from the National Registry of Myocardial Infarction 2. Circulation, vol. 97(12), pp. 11501156. ,. 1998.

[10], C. B Thompson., J. A Jakubowski., P. G Quinn,., D.Deykin, , \& C. R Valeri,. Platelet size as a determinant of platelet function. The Journal of laboratory and clinical medicine, vol. 101(2), pp. 205-213. 1983.

[11] P.AUKRUST, , T.Waehre, , J. K DAMÅS,., L Gullestad,., \& N. O Solum,. Inflammatory role of platelets in acute coronary syndromes. 2001.

[12] Z Acar,., M. T Aga,., A.Kris, , L Korkmaz,., H Erkan,.., \& E Erkus,. Mean platelet vol.umen on admission is associated with further left ventricular functions in primary PTCA patients. Eur Rev Med Pharmacol Sci, vol. 16(11),pp. 1567-1569. 2012.
[13] Z.Huczek, , J.Kochman, , K. J Filipiak,.., G. J Horszczaruk,., M.Grabowski, , R Piatkowski,., ... \& G Opolski,. Mean platelet vol.ume on admission predicts impaired reperfusion and long-term mortality in acute myocardial infarction treated with primary percutaneous coronary intervention. Journal of the American College of Cardiology,vol. 46(2), pp. 284-290. 2005.

[14] X. P Sun,., Li, B. Y., J. Li, , W Zhu,. \& Q Hua,. Impact of mean platelet vol.ume on long-term mortality in Chinese patients with ST-elevation myocardial infarction. Scientific reports, vol. 6, pp.21350. 2016.

[15] X.Wang, , X. L Xu,.. X Li,. R.Zhao, , X.Yang, , \& H. L Cong,. Diagnostic value of mean platelet vol.ume combined with troponin I for acute coronary syndrome. The American journal of the medical sciences, vol. 352(2), pp. 159-165. 2016. 